\title{
Hospitality Industry Employees' Intention to Stay in Their Job after the COVID-19 Pandemic
}

\author{
Chien-Liang Chen ${ }^{1}$ and Mei-Hui Chen ${ }^{2, *}$ \\ 1 Department of Economics, National Chi Nan University, Nantou 545, Taiwan; clchen@ncnu.edu.tw \\ 2 Strategy and Development of Emerging Industries, National Chi Nan University, Nantou 545, Taiwan \\ * Correspondence: s0937116134@gmail.com
}

check for

updates

Citation: Chen, Chien-Liang, and Mei-Hui Chen. 2021. Hospitality Industry Employees' Intention to Stay in Their Job after the COVID-19 Pandemic. Administrative Sciences 11: 144. https://doi.org/10.3390/ admsci11040144

Received: 21 October 2021 Accepted: 24 November 2021 Published: 2 December 2021

Publisher's Note: MDPI stays neutral with regard to jurisdictional claims in published maps and institutional affiliations.

Copyright: (C) 2021 by the authors. Licensee MDPI, Basel, Switzerland. This article is an open access article distributed under the terms and conditions of the Creative Commons Attribution (CC BY) license (https:/ / creativecommons.org/licenses/by/ $4.0 /)$.

\begin{abstract}
The COVID-19 pandemic had a devastating effect on the tourism and hospitality industries in Taiwan, causing some small companies to cease trading and large companies to place their employees on unpaid leave. Placing employees on unpaid leave may have negatively affected the intention of hospitality employees to remain in their jobs. This study examined whether employees' job insecurity and organizational identification affected their intention to stay in their job during the COVID-19 pandemic. Previously developed scales were adopted to develop items measuring job insecurity, organizational identification, and intention to stay in a job. Responses to 515 returned questionnaires were examined. The results revealed that job insecurity significantly affects organizational identification. Both job insecurity and organizational identification significantly affected intention to stay. Few studies have used path analyses to investigate the relationships among intention to stay, job insecurity, and organizational identification. The indirect effect of organizational identification was analyzed, and evidence supporting a total effect and total indirect effect was obtained. This implies that hospitality companies seeking to retain staff during crises should promote organizational identification among staff.
\end{abstract}

Keywords: hospitality industry; job insecurity; organizational identification; intention to stay

\section{Introduction}

The outbreak of COVID-19 in 2020 created challenges and difficulties worldwide, compromising numerous industries. Among said industries, the tourism, aviation, and hospitality industries were the first to bear the brunt. To mitigate the effects of the pandemic, Taiwan began implementing border control, which prohibited foreign tourists from entering Taiwan. Such a measure ultimately devastated Taiwan's tourism and hospitality industries. Across Taiwan, numbers of domestic and foreign tourists decreased sharply because of the pandemic, and determining how to survive the challenges of such a period is a critical matter for all stakeholders in the hospitality industry, particularly employees. To address this concern, hospitality businesses have employed a series of approaches such as closing some guest rooms, initiating numerous promotions, negotiating rent reductions, and launching food and beverage delivery services.

According to the Tourism Statistics Database of the Taiwan Tourism Bureau (2021), the number of people visiting Taiwan was 694,187 in 2020 , which was a $90 \%$ drop (i.e., decrease by 7,749,837) compared with that in 2019 (i.e., 8,444,024). This drastic decrease in the number of tourists illustrates the strong negative effects on Taiwan's hospitality industry, in which many small businesses were forced to suspend their operations or even close down completely. By contrast, large businesses were compelled to streamline their personnel, mandating that their employees had to take unpaid leave. These contingency plans generated a sense of job insecurity (hereafter abbreviated as "job insecurity") in employees, changing their intention to remain and sense of trust in their company. Thus, identification of the intention of hospitality employees to stay in their job and their sense of trust in their company during such a crisis period merits investigation. 
However, studies have suggested that the relationships among employees' intention to stay in their job, job insecurity, and organizational identification are ambiguous. Furthermore, most relevant studies have not focused on the unique context of the COVID-19 pandemic era. Therefore, this study fills the gap in the literature on strategies for the retention of hospitality employees during the COVID-19 pandemic.

Blau (1964) proposed social exchange theory, which holds that an organization member's relationship with the organization is based on a mutual benefit principle, and relevant rights and obligations are developed through dialog between the member and the organization. Social exchange theory is commonly used to explain the relationship between employees and supervisors or employees and organizations. Based on social exchange theory, job insecurity is a crucial factor influencing the stability of businesses and organizations. Chen and Eyoun (2021) indicated that the increasing numbers of food and beverage industry employees being fired or forced to take leave during the COVID-19 pandemic have elevated employees' fears of losing their jobs and their sense of uncertainty for the future, leading to greater job insecurity. The COVID-19 catastrophe, coupled with the uncertain future of the tourism industry and the decline in tourism demand, has caused hotel employees to experience job insecurity. Furthermore, downsizing by organizations instills the fear of unemployment in employees, increasing their job insecurity Jung et al. (2021). Therefore, in the hospitality industry, personnel and cost-related changes following the pandemic — such as requesting that employees take or accept unpaid leave, job transfers, and reduced salaries - have caused widespread job insecurity among hospitality industry employees.

When organizations are faced with drastic and environment-changing events, organizational identification plays a critical role in bringing organizational members together. Strengthening employees' identification with their organization can help the organization remain competitive and develop sustainably (Chen and Tseng 2020). Thus, enhancing employees' identification with their organization to boost their cohesiveness during the COVID-19 pandemic is critical to ensuring that the employees work with their organization to overcome any difficulties encountered.

Employees' intention to stay in their job indicates whether they still wish to work for their organization after giving the organization their energy and effort. Factors influencing employees' intention to stay include personal factors, work-related factors, and workingenvironment-related factors (Naim and Lenkla 2016). Hsiao and Lai (2015) asserted that providing customer service is the top priority for the tourism and hospitality industries. Because employees in such industries must respond to various customer demands, they experience more intense labor and stronger emotions than do employees in other industries. Thus, enhancing such employees' identification with the operations of their organization can ensure that they work diligently for their organization, ultimately strengthening their intention to stay. To retain more employees, managers can improve systems and methods in their organization by making relevant adjustments so that employees identify with and continue to serve their organization (Lee et al. 2018).

The hospitality industry is a labor-intensive industry with many employment opportunities. Because people who work in this industry can switch company easily, the industry has high employee turnover rates, making personnel shortages a common phenomenon. Thus, determining whether employees' intention to stay in their job during the COVID-19 pandemic differs from that otherwise is worthy of investigation. Accordingly, this study examined whether employees' job insecurity and organizational identification affected their intention to stay in their job during the COVID-19 pandemic.

In accordance with the aforementioned research motivation, this study attempted to answer the following questions:

1. Does hospitality industry employees' job insecurity have a significant effect on their intention to stay in their job during the COVID-19 pandemic?

2. Does hospitality industry employees' job insecurity have a significant effect on their organizational identification during the COVID-19 pandemic? 
3. Does hospitality industry employees' organizational identification have a significant effect on their intention to stay in their job during the COVID-19 pandemic?

4. Does job insecurity affect intention to stay through organizational identification?

The answers to these questions would serve as a reference for hospitality companies wishing to retain their employees.

\section{Literature Review}

\subsection{Job Insecurity}

Job insecurity is defined as the threat to their current job perceived by an employee (Erdogan et al. 2020). Some scholars have also defined job insecurity as an employee's willingness to continue working or their views on being unemployed during a crisis and an employee's continual fear of losing their job. Job insecurity not only includes employees' fear of unemployment but also their anxiety about threats that may compromise their job status (Ali et al. 2021). Accordingly, this study defined job insecurity as the sense of insecurity that hospitality industry employees feel about their job and the anxiety they experienced about losing their job during the pandemic.

\subsection{Organizational Identification}

Organizational identification occurs when employees consider themselves as members of their organization and define themselves as a part of the group (Teresi et al. 2019). When employees perceive their values to be similar to those of their organization, they identify with their organization (Bharadwaj and Yameen 2020). When the line between employees and their organization becomes blurred, the employees have become part of their organization and agree with its values, goals, and norms (Lee et al. 2015). Therefore, this study defined organizational identification as the degree to which the values and goals of a hospitality industry employee are identical to those of their organization.

\subsection{Intention to Stay}

When an organization gives employees the opportunity to develop themselves and enhance their professional abilities, the employees establish emotional connections with, and become committed to, their organization. These feelings subsequently become the employees' intention to stay in their job (Naim and Lenkla 2016). The emotional connection between an employee and their organization, or even an employee identifying with their organizations, directly and markedly affects the employee's intention to stay stay (Valéau et al. 2019). Therefore, this study defined intention to stay as the emotional connection between an employee and their organization or the employee identifying with their organization, ultimately leading to an intention to stay.

\subsection{Job Insecurity, Organizational Identification, and Intention to Stay-Related Studies}

Few studies have used path analyses to investigate the relationship among intention to stay, job insecurity, and organizational identification. In this study, we also provided a conceptual model to explain why job insecurity exerts a significant positive effect on employees' organizational identification and intention to stay in their present jobs during the COVID-19 pandemic.

\subsubsection{Job Insecurity and Organizational Identification}

Recent studies on job insecurity have supported the social exchange theory, showing that in general, employees' job insecurity reduces their job engagement and organizational identification, suggesting that job insecurity is negatively correlated with their job engagement and organizational identification (Ngo et al. 2013; Callea et al. 2016; Chirumbolo et al. 2017). Studies have also indicated that job insecurity has a negative effect on organizational identification, resulting in decreased task performance and lower performance levels.

Piccoli et al. (2017) surveyed 201 employees and confirmed the significant negative effect of job insecurity on organizational identification. Callea et al. (2016) conducted a 
study on the effects of job insecurity on organizational identification and job performance and discovered that job insecurity has a significant effect on organizational identification. Accordingly, this study posited H1: Employees' job insecurity would have a significant effect on their intention to stay in their job.

\subsubsection{Organizational Identification and Intention to Stay}

The social exchange theory posits that employees' strong organizational identification is positively correlated with their intention to stay because organizational identification is employees' views of the common destiny they share with their organizations. Rolf et al. (2004) stated that group members' identities in their respective groups are also their crucial social identities. Bharadwaj and Yameen (2020) noted that organizational identification is a critical factor influencing employees' intention to stay. Bharadwaj and Yameen (2020) surveyed business employees and found that organizational identification had a significant positive effect on intention to stay. The same finding was obtained by Kim et al. (2020) through a survey of 203 business employees. Accordingly, this study posited H2: Employees' job insecurity would have a significant effect on their organizational identification.

\subsubsection{Job Insecurity and Intention to Stay}

Regarding the effects of employees' job insecurity on their turnover intention, most scholars believed that employees' job insecurity increases their turnover intention and decreases their intention to stay. Ashford et al. (1989) asserted that employees' job insecurity increases their turnover intention. Sverke et al. (2002) remarked that employees' job insecurity has a significant effect on enhancing their turnover intention. Hellgren et al. (1999) conducted a longitudinal study on 375 employees in a Swedish company by using a twodimensional, both qualitative and quantitative, job insecurity scale, where the company was in the process of downsizing. The results showed that after controlling positive and negative affective factors, job insecurity was positively correlated with turnover intention.

Ribeiro et al. (2016) discovered that job insecurity increases intention to leave. Thus, job insecurity can be concluded to significantly and negatively affect intention to stay. Fan and Wang (2013) studied bank employees and indicated that the higher a person's job security, the weaker their intention to leave their job. Thus, the higher is job insecurity, the stronger the intention to leave and the weaker the intention to stay. Zhao and Liang (2015) discovered that new employees' job insecurity had a significant negative effect on their intention to stay. Accordingly, this study posited H3: Employees' organizational identification would have a significant effect on their intention to stay in their job.

Because the aforementioned studies noted the significant effect of job insecurity on organizational identification and that of organizational identification on intention to stay, this study investigated whether organizational identification mediated the effect of job insecurity on intention to stay. Accordingly, this study posited H4: Employees' job insecurity would affect their intention to stay in their job through the mediation of organizational identification.

With regard to the above hypotheses, a conceptual model was developed to illustrate the connections among job insecurity, organizational identification, and intention to stay, as displayed in Figure 1. 


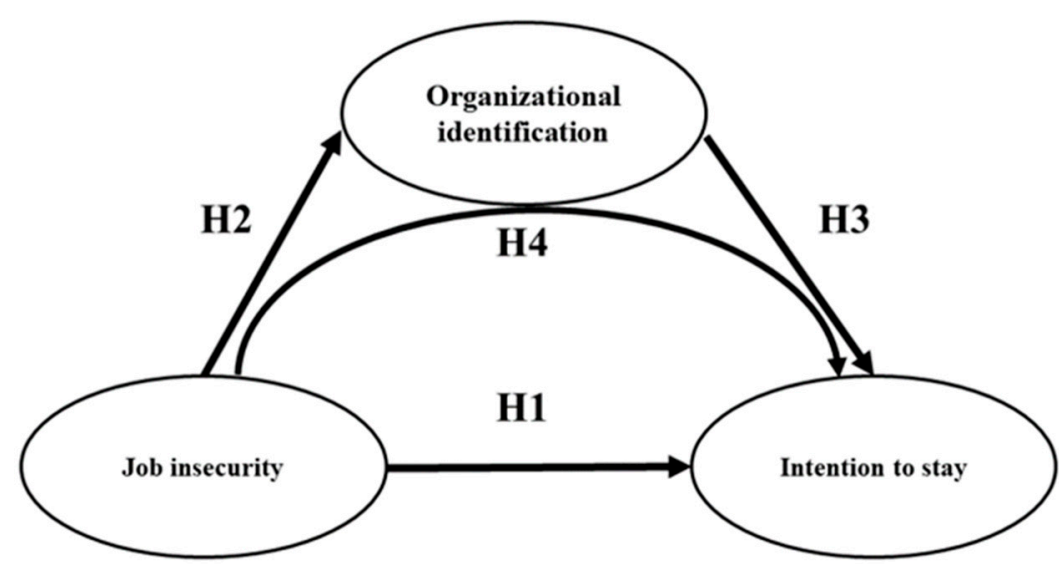

Figure 1. Conceptual model of the hypothesized relationships among job insecurity, organizational identification, and intention to stay.

\section{Methods}

\subsection{Sampling Method and Questionnaire Design}

This study used structured questionnaires scored using a 7-point Likert scale, where 1 and 7 represented strongly disagree and strongly agree, respectively. Questionnaire items were created after referencing scales with favorable reliability and validity in related studies. The questionnaire was pretested before analysis by using the expert review method. The job insecurity items were adapted from the scale introduced by Ali et al. (2021). The items measuring organizational identification were revised from the scale proposed by Lyngdoh et al. (2018). The intention to stay items were adapted from the scale presented by Tsai and Chang (2015). All three dimensions contained seven items, resulting in a total of 21 items. The second part of the questionnaire collected the hospitality industry employees' demographic information-sex, age, marital status, educational level, job seniority (their number of years in their job), job level, monthly income, and job content.

The questionnaire was distributed using an online Google form to employees of star-rated hotels throughout Taiwan from March through June, 2021. A total of 550 questionnaires were issued, of which 530 were returned and 515 were valid. We evaluated for possible common method bias by conducting Harman's one-factor test (Podsakoff and Organ 1986), and the results suggested no common method bias problem was present. On the basis of the survey data, multivariate analyses including frequency distribution, descriptive statistics, and regression were conducted. Bootstrapping was employed to analyze the mediating effects of variables. Cronbach's $\alpha$ was calculated to assess internal consistency.

\subsection{Analysis Method}

This study used SPSS 24 in analysis. Multivariate was conducted, including frequency distribution, descriptive statistics, and path analyses. Subsequently, the Bootstrap method was employed to analyze the mediating effects of variables. We assessed the normality, independence, and constant variance (Schmidt and Finan 2018) of the error term in regression analysis. When work insecurity was considered the independent variable and organizational identity the dependent variable, the Durbin-Watson (DW), KolmogorovSmirnov (KS), and Shapiro-Wilk (SW) test results were 1.912, 0.090, and 0.113, respectively. When work insecurity and organizational identity were considered independent variables and intention to stay was a dependent variable, the DW, KS, and SW test results were $2.065,0.235$, and 0.437 , respectively. DW was close to 2 , suggesting the independence of the model specification, and the KS and SW values indicated that normality assumptions were not rejected. The standardized residuals and spread of predicted values revealed no evidence of heteroscedasticity. Therefore, the data used in this study exhibited acceptable independence, normality, and homoscedasticity, and regression analysis was justified. 


\section{Results}

\subsection{Sample Data}

A total of 515 returned questionnaires were examined in this study. Regarding sex, 321 respondents were female (62.33\%). Those aged 31-40 years accounted for most of the sample $(258,50.1 \%)$. Unmarried respondents were predominant $(278,53.98 \%)$. The vast majority of respondents were a university graduate $(388,75.34 \%)$. Regarding seniority, the most common number of years in the job was $3-5$ years $(188,36.5 \%)$. More than half were basic-level employees (337, 65.44\%). The most common monthly income was NT\$25,001-50,000 (326, 63.3\%). Regarding job content, most of the respondents did work that was not directly related to sales $(313,60.78 \%)$.

\subsection{Descriptive Statistics}

According to Table 1, the means and standard deviations of the item scores ranged from 4.24 to 5.03 and from 1.17 to 1.53 , respectively. For job insecurity, the internal consistency (Cronbach's $\alpha$ ) of the seven items was 0.93. For organizational identification and intention to stay, Cronbach's $\alpha$ was 0.94 and 0.94, respectively.

Table 1. Descriptive statistics.

\begin{tabular}{|c|c|c|c|}
\hline Constructs/Items & Mean & SD & Cronbach's $\alpha$ \\
\hline \multicolumn{4}{|l|}{ Job insecurity } \\
\hline I may be transferred to another position inside my company because of the pandemic & 4.48 & 1.29 & 0.93 \\
\hline My working hours may become irregular because of the pandemic & 4.83 & 1.34 & \\
\hline I may be transferred to a job location far away because of the pandemic & 4.29 & 1.41 & \\
\hline I may lose my job because of the pandemic & 4.54 & 1.53 & \\
\hline My department may be shut down because of the pandemic & 4.24 & 1.46 & \\
\hline I may be asked to take a lot of unpaid leave because of the pandemic & 4.68 & 1.42 & \\
\hline I may be forced to take a pay cut because of the pandemic & 4.53 & 1.46 & \\
\hline \multicolumn{4}{|l|}{ Organizational identification } \\
\hline $\begin{array}{l}\text { I often mention my company when talking with friends because it is a company worth } \\
\text { working for }\end{array}$ & 4.69 & 1.17 & 0.94 \\
\hline My values are very similar to those of my company & 4.70 & 1.22 & \\
\hline I proudly tell others that I am a member of my company & 4.73 & 1.26 & \\
\hline I am very happy to be working for my company & 4.91 & 1.20 & \\
\hline I agree with the measures taken by my company with respect to treatment of employees & 4.72 & 1.20 & \\
\hline I care about the future of my company & 5.03 & 1.28 & \\
\hline As far as I am concerned, this is the best company I have ever worked for & 4.56 & 1.33 & \\
\hline \multicolumn{4}{|l|}{ Intention to stay } \\
\hline I hardly ever think about quitting & 4.77 & 1.38 & 0.94 \\
\hline I think it is the right decision to continue working at my company & 4.90 & 1.23 & \\
\hline Even if there was a better opportunity, I would not consider quitting my job & 4.40 & 1.44 & \\
\hline I feel obligated to continue working at my company & 4.86 & 1.28 & \\
\hline I would feel guilty if I were to leave my company & 4.42 & 1.34 & \\
\hline I do not want to leave my company no matter how much the company changes & 4.28 & 1.37 & \\
\hline I am very loyal to my company. & 4.68 & 1.26 & \\
\hline
\end{tabular}




\subsection{Path Analyses}

As shown in Table 2, $t$ value of job insecurity's effect on organizational identification was $9.453(p=0.000<0.05)$, indicating that job insecurity had a significant effect on organizational identification, supporting $\mathrm{H} 1$. Job insecurity explained $14.8 \%$ of the variance in organizational identification. The $t$ value of job insecurity's effect on intention to stay was $3.525(p=0.000<0.05)$, showing that job insecurity had a significant effect on intention to stay, supporting $\mathrm{H} 3$. The $t$ value of organizational identification's effect on intention to stay was $14.945(p=0.000<0.05)$, revealing that organizational identification had a significant effect on intention to stay, supporting H2. Job insecurity and organizational identification explained $38.6 \%$ of the variance in intention to stay.

Table 2. Path-analysis-based significance analyses.

\begin{tabular}{|c|c|c|c|c|c|c|c|}
\hline \multirow{2}{*}{ Dependent Variable } & \multirow{2}{*}{ Independent Variable } & \multicolumn{2}{|c|}{$\begin{array}{l}\text { Nonstandardized } \\
\text { Coefficient }\end{array}$} & \multirow{2}{*}{$\begin{array}{c}\begin{array}{c}\text { Standardized } \\
\text { Coefficient }\end{array} \\
\text { B }\end{array}$} & \multirow{2}{*}{$t$ Value } & \multirow{2}{*}{$p$ Value } & \multirow{2}{*}{$\begin{array}{c}\begin{array}{c}\text { Explained } \\
\text { Variation }\end{array} \\
\mathbf{R}^{2}\end{array}$} \\
\hline & & B & $\begin{array}{l}\text { Standard } \\
\text { Deviation }\end{array}$ & & & & \\
\hline \multirow[t]{2}{*}{$\begin{array}{c}\text { Organizational } \\
\text { identification (OIDE) }\end{array}$} & Constant & 3.222 & 0.169 & & 19.113 & 0.000 & 0.148 \\
\hline & Job insecurity (JINS) & 0.342 & 0.036 & 0.385 & 9.453 & 0.000 & \\
\hline \multirow[t]{3}{*}{ Intention to stay (RINT) } & Constant & 1.209 & 0.200 & & 6.056 & 0.000 & 0.386 \\
\hline & Job insecurity (JINS) & 0.125 & 0.035 & 0.132 & 3.525 & 0.000 & \\
\hline & $\begin{array}{c}\text { Organizational } \\
\text { identification (OIDE) }\end{array}$ & 0.596 & 0.040 & 0.559 & 14.945 & 0.000 & \\
\hline
\end{tabular}

Intermediary Effect Analysis

Organizational identification mediated the effect of job insecurity (independent variable) on intention to stay (dependent variable), making organizational identification a mediating variable in this study. Indirect effect and confidence interval tests were performed to verify whether the mediating effect was present.

According to the analyses of the indirect effects of the mediating variable, as shown in Table 3 , the total effect of job insecurity on retention intention had $p<0.05$ and a confidence interval that did not include 0 (i.e., $0.234-0.423$ ), supporting the existence of the total effect. The total indirect effect of job insecurity on retention intention through organizational identification had $p<0.05$ and a confidence interval that did not include 0 (i.e., $0.144-0.274$ ), supporting the existence of the total indirect effect and validating the mediating effect of organizational identification on the relationship between job insecurity and intention to stay.

Table 3. Analyses of the indirect effect of the mediating variable.

\begin{tabular}{|c|c|c|c|c|c|c|}
\hline \multirow{3}{*}{ Effect } & \multirow{3}{*}{$\begin{array}{l}\text { Point } \\
\text { Estimate }\end{array}$} & \multirow{2}{*}{\multicolumn{3}{|c|}{ Product of Coefficients }} & \multirow{2}{*}{\multicolumn{2}{|c|}{$\begin{array}{c}\text { Bootstrap } 1000 \text { Times } \\
\text { Bias-Corrected 95\% }\end{array}$}} \\
\hline & & & & & & \\
\hline & & $\begin{array}{l}\text { Standard } \\
\text { Error }\end{array}$ & $z$ Value & $p$ Value & $\begin{array}{l}\text { Lower } \\
\text { Bound }\end{array}$ & $\begin{array}{l}\text { Upper } \\
\text { Bound }\end{array}$ \\
\hline $\begin{array}{l}\text { Total effect } \\
\text { JINS } \rightarrow \text { RINT }\end{array}$ & 0.329 & 0.049 & 6.731 & 0.000 & 0.234 & 0.423 \\
\hline $\begin{array}{l}\text { Total indirect effect } \\
\text { JINS } \rightarrow \text { OIDE } \rightarrow \text { RINT } \\
\text { Direct effect }\end{array}$ & 0.204 & 0.032 & 6.289 & 0.000 & 0.144 & 0.274 \\
\hline $\mathrm{JINS} \rightarrow$ RINT & 0.125 & 0.049 & 2.564 & 0.010 & 0.035 & 0.230 \\
\hline
\end{tabular}




\section{Conclusions and Recommendations}

\subsection{Conclusions}

In this study, we examined whether employees' job insecurity and organizational identification affected their intention to stay in their present job during the COVID-19 pandemic. We compared our results with those reported in related literature. Our results revealed that job insecurity had a significant positive effect on organizational identification during the pandemic, a finding that contradicts those of Piccoli et al. (2017) and Callea et al. (2016). We conjecture that during the pandemic, job insecurity was presumably influenced by the government's policies, and thus employer and employee cohesiveness was strengthened, leading to the positive causal relationship between job insecurity and organizational identification; similar to the findings of Fan and Wang (2013). Moreover, our results suggest that organizational identification significantly strengthens intention to stay, a finding that supports those of Bharadwaj and Yameen (2020) and Kim et al. (2020). This signified that during the pandemic, although employees worried about their job prospects and perceived all industries to be experiencing an economic slump, they were willing to stay in their job and that organizational identification plays a crucial rule in strengthening hospitality industry employees' intention to stay during such economic crisis.

In summary, our results were consistent with the predictions of the theoretical model. The significant positive effect of job insecurity on organizational identification observed contradicts the findings of Piccoli et al. (2017) and Callea et al. (2016). Regarding job insecurity and intention to stay, our findings are consistent with those of Fan and Wang (2013). Organizational identification and intention to stay accords with the findings of Bharadwaj and Yameen (2020) and Kim et al. (2020).

\subsection{Recommendations}

How employees thought during the pandemic differed from that at other times. However, a company's management and environment are truly revealed only at times of crisis. Among the items used in this study to assess job insecurity, the highest mean was obtained for "My working hours may become irregular because of the pandemic," showing that when hospitality companies decrease employee working hours, the employees are likely to perceive job insecurity. Thus, companies should plan different work schedules for off seasons, peak seasons, and pandemic times and announce such schedules during educational training to enable employees to prepare and make relevant arrangements in advance. Among the items used to assess organizational identification and intention to stay, only "I care about the future of my company" achieved a high score, revealing that the hospitality industry is an industry with a high turnover rate and indicating that hospitality companies should enhance their recruitment and training operations to respond to various situations.

This study is one of few to document the significant pairwise relationship among job insecurity, organizational identification, and intention to stay by using path analyses. However, the study entailed several limitations. Cultural practices and epidemic prevention measures differ among countries, industries, and employers. In addition, the durations of outbreaks and severity of the pandemic's impact vary by country, so does the impact on the hospitality industry. Accordingly, the influence of the duration of COVID-19 outbreak on the hospitality industry warrants further investigation. Moreover, differences in employee position or seniority may result in distinct effects on their intention to stay, job insecurity, and organizational identification. A key policy implication derived from the current findings is that establishing favorable relationships with employees and promoting their organizational identification can help strengthen their intention to maintain their present organizational role.

Author Contributions: Conceptualization, M.-H.C.; methodology, M.-H.C.; software, M.-H.C.; validation, M.-H.C.; formal analysis, M.-H.C. and C.-L.C.; data curation, M.-H.C. and C.-L.C.; writingoriginal draft preparation, M.-H.C.; writing—review and editing, M.-H.C. and C.-L.C.; visualization, 
M.-H.C.; supervision, C.-L.C.; funding acquisition, C.-L.C. All authors have read and agreed to the published version of the manuscript.

Funding: Chien-Liang Chen acknowledges financial support by the Center for Research in Econometric Theory and Applications (Grant No. 109L900201, 110L900201) from The Featured Areas Research Center Program within the framework of the Higher Education Sprout Project by the Ministry of Education, and by the Ministry of Science and Technology (MOST 109-2634-F-002-045; MOST 110-2634-F-002-045; MOST 108-2410-H-260-038-MY2).

Institutional Review Board Statement: Not applicable.

Informed Consent Statement: Not applicable.

Data Availability Statement: Not applicable.

Acknowledgments: Authors would like to thank three anonymous referees for their constructive comments.

Conflicts of Interest: The authors declare no conflict of interest.

\section{References}

Ali, Murad, Imran Ali, Gema Albort-Morant, and Antonio Luis Leal-Rodríguez. 2021. How do job insecurity and perceived well-being affect expatriate employees' willingness to share or hide knowledge? International Entrepreneurship and Management Journal 17: 185-210. [CrossRef]

Ashford, Susan J., Cynthia Lee, and Phillip Bobko. 1989. Content, cause, and consequences of job insecurity: A theory-based measure and substantive test. Academy of Management Journal 32: 803-29.

Bharadwaj, Shubhangi, and Mohammad Yameen. 2020. Analyzing the mediating effect of organizational identification on the relationship between CSR employer branding and employee retention. Management Research Review 44: 718-37. [CrossRef]

Blau, Peter. 1964. Exchange and Power in Social Life. New York: Wiley.

Callea, Antonino, Flavio Urbini, and Antonio Chirumbolo. 2016. The mediating role of organizational identification in the relationship between qualitative job insecurity, OCB and job performance. Journal of Management Development 35: 735-46. [CrossRef]

Chen, Han, and Khalid Eyoun. 2021. Do mindfulness and perceived organizational support work? Fear of COVID-19 on restaurant frontline employees' job insecurity and emotional exhaustion. International Journal of Hospitality Management 94: 1-10. [CrossRef]

Chen, Ming-Shiun, and Hui-Chen Tseng. 2020. Research on the importance of organizational identification of the transformation process of NTPBs. Journal of Business Administration 45: 151-72.

Chirumbolo, Antonio, Flavio Urbini, Antonino Callea, and Alessandra Talamo. 2017. The impact of qualitative job insecurity on identification with the organization- The moderating role of overall organizational justice. Swiss Journal of Psychology 76: 117-23. [CrossRef]

Erdogan, Berrin, Zahide Karakitapoğlu-Aygün, David E. Caughlin, Talya N. Bauer, and Lale Gumusluoglu. 2020. Employee overqualification and manager job insecurity: Implications for employee career outcomes. Human Resource Management 59: 555-67. [CrossRef]

Fan, Guan-Hua, and You-Jiang Wang. 2013. Factors influencing first-time contract workers' intention to stay: A case study on contract worker teams hired by commercial banks in Beijing and Tianjin. Modernized Management 2: 56-59.

Hellgren, Johnny, Magnus Sverke, and Kerstin Isaksson. 1999. A two-dimensional approach to job insecurity: Consequences for employee attitudes and well-being. European Journal of Work and Organizational Psychology 8: 179-95. [CrossRef]

Hsiao, Ching-Ya, and Yu-Ting Lai. 2015. The study on employees' job satisfaction and intention to stay in the international tourist hotel industry: Take the workplace well-being as intervening variables. Journal of Tourism and Leisure Management 3: 31-42.

Jung, Hyo Sun, Yoon Sik Jung, and Hye Hyun Yoon. 2021. COVID-19: The effects of job insecurity on the job engagement and turnover intent of deluxe hotel employees and the moderating role of generational characteristics. International Journal of Hospitality Management 92: 1-9. [CrossRef] [PubMed]

Podsakoff, Philip M., and Dennis W. Organ. 1986. Self-Reports in Organizational Research: Problems and Prospects. Journal of Management 12: 531-44. [CrossRef]

Kim, Jungsun Sunny, John Milliman, and Anthony Lucas. 2020. Effects of CSR on employee retention via identification and quality-ofwork-life. International Journal of Contemporary Hospitality Management 32: 1163-79. [CrossRef]

Lee, Chia-Ling, Chun-Ming Ho, and Hsiao-Wei Ching. 2018. Leadership style, job involvement, and intent to stay: Evidence from hospitality interns in Taiwan. Travel and Tourism 15: 77-100.

Lee, Eun-Suk, Tae-Youn Park, and Bonjin Koo. 2015. Identifying organizational identification as a basis for attitudes and behaviors: A meta-analytic review. Psychological Bulletin 141: 1049-82. [CrossRef] [PubMed]

Lyngdoh, Teidorlang, Annie H. Liu, and Guda Sridhar. 2018. Applying positive psychology to selling behaviors: A moderatedmediation analysis integrating subjective well-being, coping and organizational identity. Journal of Business Research 92 : 142-53. [CrossRef] 
Naim, Mohammad Faraz, and Usha Lenkla. 2016. Knowledge sharing as an intervention for Gen Y employees' intention to stay. Industrial and Commercial Training 48: 142-8. [CrossRef]

Ngo, Hang-yue, Raymond Loi, Sharon Foley, Xiaoming Zheng, and Lingqing Zhang. 2013. Perceptions of organizational context and job attitudes: The mediating effect of organizational identification. Asia Pacific Journal of Management 30: 149-68. [CrossRef]

Piccoli, Beatrice, Antonino Callea, Flavio Urbini, Antonio Chirumbolo, Emanuela Ingusci, and Hans De Witte. 2017. Job insecurity and performance: The mediating role of organizational identification. Personnel Review 46: 1508-22. [CrossRef]

Ribeiro, Stella, Anita Bosch, and Jurgen Becker. 2016. Retention of women accountants: The interaction of job demands and job resources. SA Journal of Human Resource Management 14: 11-21. [CrossRef]

Rolf, Van Dick, Oliver Christ, Jost Stellmacher, Ulrich Wagner, Oliver Ahlswede, Cornelia Grubba, Martin Hauptmeier, Corinna Hoehfeld, Kai Moltzen, and A. Tissington Patrick. 2004. Should I stay or should I Go? Explaining turnover intentions with organizational identification and job satisfaction. British Journal of Management 15: 351-60.

Schmidt, Amand F., and Chris Finan. 2018. Linear regression and the normality assumption. Journal of Clinical Epidemiology 98: 146-51. [CrossRef] [PubMed]

Sverke, Magnus, Johnny Hellgren, and Katharina Näswall. 2002. No security: A meta-analysis and review of job insecurity and its consequences. Journal of Occupational Health Psychology 7: 242. [CrossRef]

Teresi, Manuel, Davide Dante Pietroni, Massimiliano Barattucci, Valeria Amata Giannella, and Stefano Pagliaro. 2019. Ethical climate (s), organizational identification, and employees' behavior. Frontiers in Psychology 10: 1356-68. [CrossRef]

Tourism Statistics Database of the Taiwan Tourism Bureau. 2021. Visitor Arrivals by Gender and Reasons for Visit. Available online: https:/ / stat.taiwan.net.tw/statistics/year/inbound/gender (accessed on 19 April 2021).

Tsai, Chung-Ting, and Yu-Ling Chang. 2015. The criterion-related validity of the financial personnel personality test by prove the relationship between personality, job performance, job satisfaction and willingness to stay: Take Bank P as an example. Cross-Strait Banking and Finance 3: 1-46.

Valéau, Patrick, Pascal Paille, Christel Dubrulle, and Henri Guenin. 2019. The mediating effects of professional and organizational commitment on the relationship between HRM practices and professional employees' intention to stay. The International Journal of Human Resource Management 32: 1-37. [CrossRef]

Zhao, Chenhui, and Yan Liang. 2015. A longitudinal analysis of the effect of new employees' job insecurity on their performance and intention to stay. Science $\mathcal{E}$ Technology Progress and Policy 32: 149-55. 